\title{
Um Modelo Macrodinâmico Pós- Keynesiano de Consistência entre Estoques e Fluxos para uma Economia Aberta
}

\author{
Alexandre M. F. Sarquis* \\ José Luis Oreiro**
}

\begin{abstract}
The present article aims to articulate the main contributions of Post-Keynesian Approach by means of a macrodynamic model stock and flow consistent for an open economy that is capable to produce endogenous bur irregular fluctuations for the growth rate of real output, being such fluctuations caused, at large, by the dynamics of financial fragility. The theoretical model developed in the article will be simulated in computer in order to reproduce some stylized facts of the dynamic of capitalist developed economies. An important element to be analyzed by such a model is the possibility of occurrence of a sudden fall of the output level (a depression) from the endogenous dynamics of the system.
\end{abstract}

KEY WORDS | Post Keynesian Macroeconomics, Stock and Flow Consistency, Simulation Model, Real-Financial sector interactions.

RESUMO | O presente artigo tem por objetivo articular as principais contribuições do enfoque pós-keynesiano, no contexto de um modelo macrodinâmico com consistência entre estoques e fluxos para uma economia aberta que seja capaz de produzir flutuações endógenas e irregulares para a taxa de crescimento do produto real, sendo tais flutuações resultantes, em larga medida, da dinâmica da fragilidade financeira. O modelo teórico desenvolvido no artigo será simulado em computador com vistas à reprodução de alguns fatos estilizados da dinâmica das economias capitalistas desenvolvidas. Um elemento importante a ser analisado por intermédio desse modelo é a possibilidade de ocorrência de uma queda abrupta do nível de produção (depressão) a partir da dinâmica endógena do sistema.

PALAVRAS-CHAVE | Macroeconomia pós-Keynesiana, Consistência entre Estoques e Fluxos, Modelo de Simulação, Interações real-financeiro.

Aluno do Programa de Doutorado em Economia da Universidade de Brasília. E-mail: alexandre.sarquis@camara.gov.br.

" Professor Adjunto do Instituto de Economia da Universidade Federal do Rio de Janeiro, Pesquisador Nível 1B do CNPq e Presidente da Associação Keynesiana Brasileira. E-mail: jose.oreiro@ie.ufrj.br. 



\section{INTRODUÇÃO}

No contexto da macroeconomia pós-keynesiana podemos identificar ao menos duas vertentes, uma relacionada com a assim chamada "escola de Cambridge", cujo foco de análise é a teoria do crescimento e da distribuição de renda, e uma outra vertente relacionada com o assim chamado "keynesianismo fundamentalista", cujo foco é o papel do tríduo tempo-incerteza-moeda sobre a dinâmica das economias capitalistas. Essa pluralidade de vertentes resultou na inexistência de um arcabouço teórico unificado que fosse capaz de apresentar de forma coerente as proposições da escola póskeynesiana, o que a colocaria como uma alternativa viável ao mainstream (Godley e Lavoie, 2007, p.3).

A metodologia empregada pelos economistas pós-keynesianos, em ambas as vertentes, tem sido uma metodologia eminentemente Marshalliana, a qual consiste em "olhar para as partes da economia em seqüência, mantendo constante ou abstraindo o que está acontecendo, ou pelo menos os efeitos do que está acontecendo, nas outras partes do sistema” (Harcourt, 2006, p. 277). Dessa forma, os modelos pós-keynesianos que lidam com temas como produção, inflação, desemprego, fluxos financeiros e etc são constituídos por "peças separadas", sem nenhuma preocupação a respeito de como o sistema como um todo funciona, o que exigiria a integração desses "modelos particulares" num modelo geral a respeito do funcionamento da economia (Godley e Lavoie, 2007, p.6).

No entanto, podemos observar nos últimos anos o surgimento de uma literatura que afirma que a integração entre as diversas vertentes do pensamento pós-keynesiano pode ser feita por intermédio da construção de modelos stock-flow consistent (Dos Santos, 2006; Zezza e Dos Santos, 2004, Godley e Lavoie, 2007; Dos Santos e Macedo e Silva, 2009). Essa abordagem teria sido inspirada a partir dos escritos de James Tobin, particularmente na assim chamada "abordagem de equilíbrio geral" para a macroeconomia monetária. Segundo Tobin (1982), essa abordagem possui as seguintes características: 
A) Análise cuidadosa da evolução dos diversos estoques ao longo do tempo por intermédio de relações contábeis bem definidas.

B) Inclusão de diversos ativos e taxas de retorno nos modelos macroeconômicos.

C) Modelagem das operações financeiras e de política monetária.

D) Inclusão da restrição orçamentária tanto para os indivíduos tomados isoladamente como para a economia com um todo.

O aspecto essencial dos modelos stock-flow consistent (doravante SFC) é, contudo, a utilização de um sistema logicamente completo de identidades contábeis que permitam que todos os fluxos tenham uma contra-partida correspondente em termos de variação de estoques e que toda a riqueza existente na economia seja inteiramente alocada entre os diversos agentes e setores da economia em consideração. Essa consistência entre fluxos e estoques garante a existência de uma dinâmica intrínseca ao sistema de tal forma que a economia não pode nunca ser vista como um sistema estático, mas sim como um sistema que evolui ao longo do tempo (Godley e Lavoie, 2007, p.13). Entendido dessa forma, os modelos SFC devem ser vistos como um requerimento mínimo indispensável para a construção de qualquer teoria séria e consistente a respeito da dinâmica das economias capitalistas.

Embora a consistência entre fluxos e estoques seja fundamental para a teorização em economia, a mesma não é suficiente para garantir bons resultados teóricos. Com efeito, o comportamento do modelo e os seus resultados dependem das equações comportamentais associadas às identidades contábeis. Essas equações irão definir o assim chamado "fechamento" ou "causalidade" do modelo. O "fechamento" envolve, segundo Taylor (1991), a definição das variáveis endógenas e exógenas num sistema de equações; o que exige, por seu turno, uma boa dosagem de intuição e senso histórico para separar umas das outras.

Nesse contexto, os diferentes paradigmas da teoria econômica podem ser diferenciados com base em diferentes fechos para um mesmo sistema de relações contábeis. O "fecho" neoclássico pode então ser definido como uma situação na qual: (i) os agentes econômicos tomam decisões com base na maximização de alguma função objetivo, de tal forma que as "equações comportamentais" resultam de algum processo de otimização; e (ii) a produção é um processo essencialmente atemporal de tal forma que a existência de moeda e crédito é vista como um acréscimo desnecessário a estrutura dos modelos formais. Dessa forma, os modelos neoclássicos SFC tendem a apresentar uma estrutura analítica extremamente simplificada, recorrendo-se usualmente ao modelo de Agente-Representativo no qual a riqueza existente na economia pode ser mantida em um ou dois ativos, no máximo ${ }^{1}$.

Os modelos SFC de cunho pós-keynesiano apresentam uma estrutura analítica bem mais complexa. Primeiramente, a ênfase na importância do tempo para os processos econômicos faz com que seja impossível desconsiderar a existência de moeda e crédito na estrutura dos mo-

1 Vide, por exemplo, o modelo de Ransey onde o único ativo é o capital; e o modelo de Sidrauski, onde a riqueza pode ser mantida na forma de moeda e capital (Blanchard e Fischer, 1989, caps.2 e 4). 
delos em consideração. Dessa forma, tais modelos devem supor a existência de um sistema bancário, devendo assim modelar a inter-relação entre o mesmo e o assim chamado "setor produtivo". Além disso, a riqueza existente na economia pode assumir diversas formas o que exige a modelagem da decisão de composição de portfólio, bem como um cuidado especial com a contabilização correta dos diversos estoques de ativos entre os diferentes agentes e setores da economia. Por fim, a consideração de que os agentes econômicos possuem racionalidade limitada no sentido de Simon (1959), de tal forma que as suas decisões direcionadas para a obtenção de resultados satisfatórios, os quais são medidos por intermédio de "metas" ou "alvos" para certas variáveis; faz com que as equações comportamentais sejam, na maior parte das vezes, descritas como "funções de reação", onde se especifica como os agentes/setores irão reagir face à ocorrência de certos desequilíbrios.

Em função da maior complexidade dos modelos SFC pós-keynesianos, os quais envolvem a análise das inter-relações entre os portfólios de diversos agentes e setores da economia; segue-se que a solução dos mesmos envolve, em geral, a simulação em computador, ao invés do método tradicional de obtenção de solução analítica fechada. Uma exceção importante pode ser encontrada em Dos Santos e Macedo e Silva (2009), onde se apresenta um modelo SFC simplificado que possui solução analítica fechada na forma de um steady-state.

O grande problema com a abordagem dos autores em consideração é que sob o pretexto de manter o modelo suficientemente simples para ser passível de solução analítica, os autores desconsideram uma série de outros elementos que são, não só importantes para a teoria pós-keynesiana, mas importantes para qualquer modelo relevante sobre a dinâmica das economias capitalistas. Por exemplo, os autores desconsideram completamente o lado da oferta da economia, adotando de maneira a-crítica o método fix-price de John Hicks. Ao desconsiderar o lado da oferta da economia (para manter o modelo tratável), o modelo dos autores em consideração só enfatiza os efeitos de longo-período de mudanças da demanda efetiva (e da distribuição de renda). Aqui abre-se um flanco enorme para a crítica ortodoxa, pois enseja-se o comentário de que os modelos pós-keynesianos desconsideram o "lado da oferta", por isso suas conclusões são parciais e válidas apenas para o "curto-prazo", entendido agora como o intervalo de tempo no qual os preços se mantêm fixos. Por mais que se acredite em menu-costs, o intervalo de tempo entre reajustes de preços numa economia desenvolvida é relativamente curto (menos de dois anos), de maneira que a desconsideração do lado da oferta diminui sensivelmente a relevância do modelo. Em outros termos, em nome da consistência e da simplificação, sacrifica-se a relevância.

Uma abordagem alternativa para o problema da integração entre as duas vertentes do pensamento pós-keynesiano foi feita por Oreiro e Ono (2007). Esses autores construíram um modelo embasado nos principais elementos do enfoque teórico pós-keynesiano, a saber: (i) a determinação do nível de produção pela demanda efetiva; (ii) a existência de propensões a poupar diferenciadas com base na classe de rendimentos; (iii) a fixação de preços com base num 
mark-up sobre os custos diretos unitários de produção; (iv) a determinação do investimento com base na teoria dos dois preços de Minsky; (v) a influência da estrutura de capital das empresas, em especial o seu nível de endividamento, sobre a decisão de investimento e de fixação de preços; (vi) a determinação da taxa de inflação com base no conflito distributivo entre capitalistas e trabalhadores, e (vii) a endogenidade da oferta de moeda.

O modelo Oreiro-Ono apresenta uma estrutura em linha com argumentos do enfoque teórico pós-keynesiano. Este modelo descreve o comportamento de uma economia fechada e com setor governamental na qual um único bem é produzido para consumo e para investimento. São considerados apenas dois fatores de produção, capital e trabalho.

O modelo Oreiro-Ono (2007) foi aperfeiçoado por intermédio de sucessivas "safras" de modelos macrodinâmicos dando origem aos modelos Oreiro-Passos (2008) e Oreiro-Lemos (2009). Essas duas versões modificadas do modelo Oreiro-Ono avançaram no sentido de incorporar hipóteses mais realistas a respeito das relações de causalidade entre as variáveis econômicas (endogenização do progresso tecnológico por intermédio de uma função de progresso técnico Kaldoriana, especificação mais apurada da função investimento, financiamento do déficit do governo por intermédio da venda de títulos públicos, abertura da conta de transações correntes do balanço de pagamentos), o que foi de fundamental importância para aumentar a aderência entre os resultados da simulação computacional e os "fatos estilizados" da dinâmica capitalista.

Em que pesem esses avanços, deve-se ressaltar o fato de que a família de modelos desenvolvidos a partir da contribuição original de Oreiro e Ono não explicita uma estrutura de identidades contábeis SFC; de tal forma que os modelos desenvolvidos a partir dessa contribuição original podem apresentar um problema que é conhecido por "buraco negro" na literatura em consideração².

Isso posto, o presente artigo tem por objetivo articular as principais contribuições do enfoque pós-keynesiano, no contexto de um modelo macrodinâmico SFC para uma economia aberta que seja capaz de produzir flutuações endógenas e irregulares para a taxa de crescimento do produto real, sendo tais flutuações resultantes, em larga medida, da dinâmica da fragilidade financeira. Para tanto, tomaremos como ponto de partida o modelo Oreiro-Passos (2008). Dessa forma, será construído um modelo macrodinâmico SFC para uma economia aberta a partir de uma reformulação dos blocos originais do modelo em consideração, acrescida das identidades contábeis necessárias para tornar o referido modelo consistente do ponto de vista da relação entre estoques e fluxos.

O modelo teórico desenvolvido no artigo será simulado em computador com vistas à reprodução de alguns fatos estilizados da dinâmica das economias capitalistas desenvolvidas.

2 Essa expressão encontra-se, entre outros, em Godley e Lavoie (2006, p. 14). 
Um elemento importante a ser analisado por intermédio desse modelo é a possibilidade de ocorrência de uma queda abrupta do nível de produção (depressão) a partir da dinâmica endógena do sistema.

\section{ESTRUTURA DE ESTOQUES E FLUXOS}

Nosso modelo consistirá de trabalhadores, identificados pelo subscrito $w$ quando necessário, capitalistas produtivos, identificados pelo subscrito $c$, capitalistas financeiros, identificados pelo subscrito $f$, firmas produtivas, identificadas pelo subscrito $e$, bancos, identificados peco subscrito $b$, banco central, identificado pelo subscrito $b c$, governo, identificado pelo subscrito $g$ e setor externo, identificado por *, embora o asterisco também seja utilizado para simbolizar meta ou valor ótimo, de acordo com o contexto.

\section{Tabela 1 | Balanço Patrimonial dos Agentes Institucionais}

\begin{tabular}{|c|c|c|c|c|c|c|c|c|c|}
\hline Ativos & Trab. & $\begin{array}{l}\text { Cap. } \\
\text { Produtivos }\end{array}$ & $\begin{array}{l}\text { Cap. } \\
\text { Financeiros }\end{array}$ & Firmas & Bancos & $\begin{array}{l}\text { Banco } \\
\text { Central }\end{array}$ & Govern. & $\begin{array}{l}\text { Setor } \\
\text { Externo }\end{array}$ & Total \\
\hline $\begin{array}{l}\text { Moeda Manual } \\
\text { (H) }\end{array}$ & 0 & $\mathrm{Hc}$ & $\mathrm{Hf}$ & $\mathrm{He}$ & $\mathrm{Hb}$ & $(-) H$ & 0 & 0 & 0 \\
\hline $\begin{array}{l}\text { Depósitos à } \\
\text { Vista (M) }\end{array}$ & 0 & Mc & Mf & $\mathrm{Me}$ & $(-) M$ & 0 & 0 & 0 & 0 \\
\hline $\begin{array}{l}\text { Redesconto } \\
\text { (A) }\end{array}$ & 0 & 0 & 0 & 0 & $(-) A$ & $A$ & 0 & 0 & 0 \\
\hline $\begin{array}{l}\text { Títulos } \\
\text { Públicos (B) }\end{array}$ & 0 & $\mathrm{Bc}$ & $\mathrm{Bf}$ & 0 & $\mathrm{Bb}$ & $\mathrm{Bbc}$ & $(-) B$ & 0 & 0 \\
\hline $\begin{array}{l}\text { Tíulos Inter- } \\
\text { nacionais (B*) }\end{array}$ & 0 & 0 & 0 & $\begin{array}{l}(-) \\
\text { E.B*e }\end{array}$ & $\begin{array}{l}(-) \\
\text { E.B*b }\end{array}$ & 0 & 0 & E. B* & 0 \\
\hline $\begin{array}{l}\text { Divisa Estran- } \\
\text { geira (R) }\end{array}$ & 0 & 0 & 0 & 0 & E. $\mathrm{Rb}$ & E. $\mathrm{Rbc}$ & 0 & (-) E.R & 0 \\
\hline $\begin{array}{l}\text { Empréstimos } \\
\text { Bancários (L) }\end{array}$ & 0 & 0 & 0 & $(-) L$ & $\mathrm{~L}$ & 0 & 0 & 0 & 0 \\
\hline $\begin{array}{l}\text { Ativos Reais } \\
\text { (capital) (K) }\end{array}$ & 0 & 0 & 0 & p.K & 0 & 0 & 0 & 0 & p.K \\
\hline $\begin{array}{l}\text { Patrimônio } \\
\text { Líquido (V) }\end{array}$ & 0 & Vc & Vf & Ve & 0 & 0 & $(-) B$ & E. $\left(B^{*}-R\right)$ & p.K \\
\hline
\end{tabular}

Obs:: O símbolo (-) indica uma posição devedora no ativo, ou seja, para aquele agente o ativo é, na realidade, um passivo.

A tabela 1 apresenta as relação entre credores e devedores dos ativos financeiros e reais de nossa economia artificial, vamos chamá-la de balanço patrimonial. Ela também informa algumas de nossas hipóteses teóricas, por exemplo:

(i) Bancos contratam empréstimos unicamente com Firmas;

(ii) O Banco Central não emite títulos estrangeiros;

(iii) A riqueza dos trabalhadores é igual a zero em todos os momentos. 
Os fluxos positivos, ou receitas, dos trabalhadores (salários), igualam em cada período os fluxos negativos, ou despesas (consumo). Desta forma não há excedente de riqueza a ser transportado entre períodos. Esta relação ilustra como se conectam estoques e fluxos em uma economia: alguns setores podem descasar seus embolsos e desembolsos no tempo, e este descasamento é financiado, caso seja negativo, ou aplicado, caso seja positivo, em ativos financeiros. Por sua vez, a escolha de ativos financeiros causa embolsos e desembolsos no período seguinte.

Podemos observar a consistência de estoques na Tabela 1. Analisando horizontalmente, todos os ativos financeiros têm montantes a receber (positivos) e a pagar (negativos) de forma a se cancelarem. Os ativos reais não tem devedores, uma vez que de fato existem, e deles se extrai o valor diretamente. Analisando verticalmente o Balanço Patrimonial, vemos que a riqueza sempre está denominada nos vários ativos da sociedade, não há riqueza por abstração.

O Apêndice A contém uma tabela que relaciona os fluxos monetários que sucedem a escolha de ativos. Chamaremos esta tabela de demonstrativo de resultados. Note que o rigor da consistência dos fluxos nos faz reconhecer fluxos geralmente ignorados na literatura, a exemplo da correção monetária de ativos: se um agente mantém parte dos seus ativos em moeda manual e parte em capital, a segunda parcela experimentará correção monetária automática, enquanto a primeira não. Da mesma forma se um agente estiver comprado em divisa estrangeira, uma depreciação cambial melhorará sua posição em moeda nacional. Todos os ativos foram cuidadosamente checados neste sentido.

Novamente algumas hipóteses podem ser verificadas, tais como os dividendos dos bancos são integralmente distribuídos para os capitalistas financeiros, os dividendos das firmas são parcialmente distribuídos para os capitalistas produtivos e o resultado do Banco Central é revertido para o governo. Em nosso modelo o Banco Central faz o mercado de títulos, adquirindo o excedente para completar o déficit nominal do governo, tem uma política passiva de manutenção de reservas, e atua sobre a taxa básica da economia, fixando o $i_{b c}$ que serve de base para as outras taxas de juros, e desestimula a acumulação de capital.

Os bancos não têm Patrimônio Líquido, o que consideramos uma boa aproximação da realidade, pois a indústria é fortemente alavancada. Desta forma, o resultado dos bancos é obtido unicamente por meio do spread entre as taxas de captação (remuneração dos depósitos à vista e dos títulos estrangeiros) e as taxas de aplicação (empréstimos às empresas, títulos públicos e divisa estrangeira). Todo o resultado positivo é distribuído, e todo resultado negativo é suportado pela diminuição líquida de ativos.

O setor externo é complexo, composto de uma balança de transações correntes, e uma balança de capitais, embora esta última não seja subdividida em tempos de maturação dos investimentos. 
A entrada de capitais se dá por meio de emissões de títulos estrangeiros por parte dos bancos e das firmas. Também há entrada por meio do saldo positivo da balança comercial, menos a saída em decorrência dos insumos importados da produção nacional. Esta posição do mercado de câmbio é resolvida por apreciação cambial, caso positiva, ou depreciação cambial, caso negativa (veja a seção 3.4 abaixo).

A consistência entre estoques e fluxos não é, por si só, capaz de ditar o caminho seguido pela economia. Num certo sentido, estas 49 equações determinam um espaço viável onde as variáveis do modelo (cerca de 380, incluindo dependentes e auxiliares de plotagem) podem existir consistentemente. Para que o modelo apresente um caminho seguido pela economia, são necessárias condições de contorno (valores iniciais das variáveis), e relações comportamentais entre as variáveis. Estas relações são livres até o ponto em que não "quebrem" a consistência entre estoques e fluxos. Uma conseqüência desta "liberdade restrita" é a Lei de Walras, uma vez que se $\mathrm{n}-1$ variáveis de um determinado agente, estoque ou fluxo, estiverem determinadas, a $n$ - ésima variável também estará determinada.

\section{EQUAC̣̃̃ES COMPORTAMENTAIS}

Sendo a contabilidade social insuficiente para determinar o caminho da economia, passamos a colecionar uma série de regularidades empíricas e conceitos Pós-Keynesianos para que a soma das ações de cada agente - ações que cada um percebe como livre dentro de sua própria restrição orçamentária - componham-se e causem crescimento, inflação, saldo de balança comercial e outros fenômenos agregados.

Sugerimos, então, valores para todas as variáveis em $t=0, t=1 \mathrm{e} t=3$, deixando a dinâmica tomar conta do modelo a partir de $t=3$, segundo as equações e calibragens apresentadas abaixo. Os elementos do paradigma Pós-Keynesiano incorporados no modelo são:

(i) O princípio da demanda efetiva;

(ii) Propensões a poupar diferentes para diferentes classes sociais;

(iii) Preço baseado em mark-up;

(iv) Decisão Minskyana de investimento com base na teoria dos "dois preços";

(v) A estrutura de capital das empresas influencia a sua decisão de investimento, sendo falsa, portanto, o teorema de Modigliani-Miller;

(vi) A inflação é causada pelo conflito distributivo entre Firmas e Trabalhadores;

(vii) A oferta de moeda é endógena;

(viii) Progresso técnico é endógeno no sentido de Kaldor. 


\subsection{Preços, Salários e Política Monetária}

As firmas formam preços com base num mark-up desejado, $\mathrm{Z}_{t}^{e}$, sobre os custos diretos unitários de produção, tal como na equação (1) abaixo:

$$
P_{t}=\left(1+z_{t}^{e}\right)\left[a_{t}^{0} w_{t}+a_{t}^{1} E_{t} P_{t}^{*}\right]
$$

Onde $a_{t}^{0}$ é o requisito unitário de mão-de-obra, ou seja, a quantidade real de trabalho necessária na produção de uma unidade de produto, e $a_{t}^{1}$ é o requisito unitário de insumos importados. Em todas as equações o subscrito $t$ significa "no tempo t". Os salários nominais são representados por $W_{t}$ e o preço dos insumos importados é representado por $P_{t}^{*}$, sendo $E_{t}$ a taxa de câmbio nominal.

O mark-up desejado $Z_{t}^{e}$ é determinado com base no grau de utilização da capacidade produtiva do período anterior, $u_{t-1}^{e}$ e no nível de endividamento da empresa, tal como se observa na equação (2) abaixo:

$$
z_{t}^{e}=z_{0}^{e}+z_{1}^{e} u_{t-1}^{e}+z_{2}^{e}\left(\frac{L_{t-1}+E_{t-1} B_{t-1}^{*}}{P_{t-1} K_{t-1}+M_{t-1}^{e}+H_{t-1}^{e}}\right)
$$

Suporemos que os salários nominais resultam de um processo de barganha coletiva entre firmas e sindicatos. Nesta negociação, os sindicatos demandam reajustes do salário nominal para repor as perdas inflacionárias do período, e para atingir uma meta de salário real, $\bar{V}$. Esta meta é determinada a partir de uma ponderação entre as condições prevalecentes no mercado de trabalho (expressa pela taxa de desemprego, $u^{W}$ e pelo nível da produtividade do trabalho $\left(a_{t}^{0}\right)^{-1}$. Caso o salário real efetivamente obtido no período anterior seja inferior ao salário real meta, então os sindicatos irão demandar reajustes de salários nominais acima da inflação do período anterior, como estratégia de eliminação da sua situação de "insatisfação distributiva". O reajuste dos salários nominais será tão maior quanto maior for o poder de barganha dos sindicatos, o que é aproximado por um fator $\Phi$.

Temos, então, que:

$$
\begin{aligned}
& \frac{w_{t}-w_{t-1}}{w_{t-1}}=\max \left\{0 ; \pi_{t-1}+\Phi\left(\bar{V}_{t}-V_{t-1}\right)\right\} \\
& \bar{V}_{t}=\phi_{0}-\phi_{1} u_{t-1}^{w}+\phi_{2} \frac{1}{a_{t}^{0}}
\end{aligned}
$$

A população total, $N_{t}$, que tomaremos igual à população economicamente ativa, cresce à taxa fixa $g_{N}$. 
$\mathrm{Na}$ economia em consideração prevalece um regime de Metas para Inflação ${ }^{3}$ como forma de condução da política monetária. Em outras palavras, o Banco Central tem como mandato geral a busca de uma taxa de inflação estável de longo prazo, $\pi^{l t}$, mas possui graus de liberdade para acomodar, no curto-prazo, os efeitos dos choques de oferta e de demanda sobre o nível de produção e emprego. Isso exige uma convergência gradual da inflação efetiva para a meta de longo-prazo, o que é feito por intermédio da fixação de metas de inflação de curto-prazo. A meta de inflação de curto-prazo, $\pi^{*}$, será então um compromisso entre a meta de inflação de longo-prazo, $\pi^{l t}$, e a meta do período anterior, conforme equação (5) abaixo:

$$
\pi_{t}^{*}=\pi_{t-1}^{*}+\alpha\left(\pi^{l t}-\pi_{t-1}^{*}\right)
$$

O mecanismo utilizado para buscar a meta de inflação é a taxa de juros de curto prazo, a qual é fixada com base numa Regra de Taylor (Taylor, 1993), conforme se observa na expressão (6):

$$
i_{t}^{B C}=(1-\lambda) i_{t-1}^{B C}+\lambda\left[\beta_{0}\left(\pi_{t-1}-\pi_{t}^{*}\right)+\beta_{1}\left(g_{t-1}-g_{t-1}^{*}\right)+\beta_{2}\right]
$$

Finalmente, os bancos comerciais fixam a taxa de juros de suas operações de crédito com base num mark-up sobre a taxa básica de juros determinada pelo Banco Central. Dessa forma, a base monetária da economia em consideração é totalmente endógena conforme Moore (1988). A determinação da taxa de juros das operações de crédito bancário pode ser visualizada pela equação (7) abaixo:

$$
i_{t}^{b}=\left(1+z_{t}^{b}\right) i_{t}^{B C}
$$

$\mathrm{Na}$ fixação de $Z_{t}^{b}$ os bancos levam em conta tanto a inflação do período anterior como o nível de endividamento das firmas.

$$
z_{t}^{b}=z_{0}^{b}+z_{1}^{b} \pi_{t-1}+z_{2}^{b}\left(\frac{L_{t-1}^{e}+E_{t-1} B_{t-1}^{e}}{K_{t-1}^{e}+M_{t-1}^{e}+H_{t-1}^{e}}\right)
$$

\subsection{Progresso Técnico e Restrições de Oferta.}

Suporemos a existência de economias dinâmicas de escala, a exemplo do que ocorre em modelos de learning by doing. Isto significa que a taxa de variação da produtividade do trabalho é determinada pela taxa de variação do produto real. Para melhor representar essa idéia, adotaremos a função Kaldoriana de progresso técnico (Kaldor, 1957a). Na equação que segue, $\phi_{0}^{e}$ e $\phi_{1}{ }^{e}$ são parâmetros, $\left(a_{t}^{0}\right)^{-1}$ é a produtividade (recíproco matemático da produtividade unitária do trabalho), e $g^{Y}$ é a taxa de crescimento do produto real.

3 Para ver sobre a compatibilidade entre o Regime de Metas para Inflação e a economia Pós-Keynesiana, veja Setterfield (2006). 
$\left(a_{t}^{0}\right)^{-1}=\left(a_{t-1}^{0}\right)^{-1}\left(1+\phi_{0}^{e}+\phi_{1}^{e} g_{t-1}^{Y}\right)$

O produto potencial da economia é definido como o nível de produção que resulta da conjugação de três restrições: (i) o estoque de mão-de-obra (equação 11); (ii) o nível máximo de utilização do estoque de capital (equação 10); e (iii) a variação máxima do produto real que a sociedade consegue suportar entre um período e outro, uma vez que existem custos de ajustamento do nível de produção (equação 12).

$$
\begin{aligned}
Y_{t}^{\max , K} & =u^{\max } \sigma K_{t-1} \\
Y_{t}^{\max , l} & =\frac{N_{t}}{a_{t}^{0}}\left(1-u^{\text {fict }}\right) \\
Y_{t}^{\max , g} & =g^{\max } Y_{t-1}
\end{aligned}
$$

Na equação (11), $u^{\text {frit }}$, é a taxa de desemprego friccional, a qual será considerada como uma restrição instransponível.

Por fim, o produto real será determinado pela demanda efetiva desde que sejam aquele seja inferior ao nível de produção potencial da economia. Desta forma, o produto real é dado pela relação a seguir, onde $Z$ é a demanda efetiva:

$$
Y_{t}=\min \left\{Y^{\max , k} ; Y^{\max , l} ; Y^{\max , g} ; z\right\}
$$

\subsection{Consumo e Investimento}

Vamos assumir que os gastos de consumo do governo, $C_{t}^{g}$, cresçam a uma taxa constante exógena, $g^{g}$, tal como se observa na equação (14) abaixo:

$$
C_{t}^{g}=\left(1+g_{t}^{g}\right) C_{t-1}^{g}
$$

Com relação ao investimento do governo, $I_{t}^{g}$, iremos supor que o mesmo é feito com vistas à obtenção de uma meta, $\widetilde{K}^{*}$, para a razão entre o estoque de capital público e o capital total da sociedade, conforme as equações (15) e (16) abaixo:

$$
\begin{aligned}
& \widetilde{\mathrm{K}}_{\mathrm{t}}=\frac{\mathrm{K}_{\mathrm{t}}^{\mathrm{y}}}{\mathrm{K}_{\mathrm{t}}} \\
& I_{t}^{g}=\gamma\left(\widetilde{K}_{t}^{*}-\widetilde{K}_{t-1}\right) K_{t-1}^{G}
\end{aligned}
$$


O investimento privado é determinado em um processo de dois estágios. No primeiro, os empresários determinam o estoque de capital desejado e, dado o estoque de capital herdado do período anterior, o nível de investimento desejado. O nível de capital desejado dependerá das expectativas de longo prazo e da preferência por liquidez das firmas. No segundo estágio, há o confronto das decisões de investimento com as possibilidades de financiamento, ou seja, confronta-se o investimento desejado com a restrição financeira ao mesmo.

$$
I_{t}^{d}=v_{0}\left(Y_{t}-Y_{t-1}\right)+K_{t-1}^{e}\left[v_{1}\left(\frac{P_{t}^{D}}{P_{t}^{S}}-1\right)+v_{2}+v_{3} \widetilde{K}_{t-1}\right]
$$

$\mathrm{Na}$ equação (17) está representado o primeiro estágio da decisão de investimento das firmas. Note a presença de quatro componentes distintas:

(i) Uma componente, associada ao parâmetro $\mathrm{v}_{0}$, devida ao efeito acelerador, ou seja, relacionada à variação do produto no último período;

(ii) Uma segunda componente, associada ao parâmetro $\mathrm{v}_{1}$, devida à percepção de valor presente dos investimentos de capital;

(iii) Uma terceira componente, associada ao parâmetro $\mathrm{v}_{2}$, proporcional ao estoque de capital herdado do período anterior;

(iv) E uma quarta componente, associada ao parâmetro $v_{3}$, que traduz as externalidades positivas do capital público sobre o investimento privado.

Utilizaremos, como em outras partes do modelo, uma projeção simples dos lucros do último período como a série de embolsos prováveis do estoque de capital (Possas, 1993), utilizando uma taxa de desconto simples, $d_{t}$ para chegar ao preço de demanda do estoque de capital instalado, $P_{t}^{D}$, como o valor presente de uma perpetuidade:

$P_{t}^{D}=\frac{(1-\tau) m_{t-1} P_{t-1} Y_{t-1}}{d_{t}}$

Na equação (19), $\tau$ é o imposto de renda das firmas, $m_{t}$ é participação dos lucros na renda, e $P_{t}$ é o nível geral de preços. O preço de custo dos bens de capital será tomado como sendo igual ao nível geral de preços:

$$
P_{t}^{S}=P_{t-1}
$$

A taxa de desconto aplicada na equação (19) depende de dois fatores: (i) a remuneração dos títulos públicos (uma proxy para o custo de oportunidade dos investimentos); e (ii) o risco de crédito, representado por uma média ponderada entre o risco de solvência, $\delta_{t-1}$ e o risco de liquidez, ou fragilidade financeira $f_{t-1}$. 
$d_{t}=i_{t-1}^{g}+\theta_{1} \delta_{t-1}+\theta_{2} f_{t-1}$

$\delta_{t-1}=\frac{B_{t-1}^{*}+L_{t-1}}{P_{t-1} K_{t-1}+M_{t-1}+H_{t-1}}$

$f_{t-1}=\frac{i_{t-1}^{*} B_{t-1}^{*}+i_{t-1} L_{t-1}}{m_{t-1} P_{t-1} Y_{t-1}}$

Uma vez determinado o investimento desejado, os empresários devem comparar o investimento que deseja realizar com a sua restrição financeira. Essa restrição é determinada com base no endividamento máximo que as firmas estão dispostas a aceitar como proporção do valor do seu estoque de capital, no estoque total de empréstimos já contratados junto ao setor bancário e o fluxo líquido de caixa do período corrente. A restrição financeira pode, então, ser apresentada pela equação (24) abaixo:

$F_{t}=\delta_{\max } P_{t-1} K_{t-1}-L_{t-1}+\vartheta(1-\tau)\left[P_{t-1} Y_{t-1}-w_{t-1} N_{t-1}-\left(i_{t-1}+\gamma^{i}\right) L_{t-1}\right]$

Na equação acima (24) $\delta_{\max }$ é o fator de endividamento máximo, $\tau$ é o imposto de renda para as empresas, $\gamma^{i}$ é o fator de amortização dos empréstimos bancários, e $\vartheta$ é o peso da capacidade de pagamento na restrição. Finalmente é possível o cálculo do investimento efetivo do período como o mínimo entre o desejado e a restrição financeira:

$$
I_{t}=\min \left\{I_{t}^{D} ; F(t)\right\}
$$

Quanto aos gastos de consumo, iremos assumir a existência de propensões a consumir diferenciadas sobre salários e lucros, tal como Kaldor (1956) e Pasinetti (1962). Mais especificamente, iremos considerar que "os trabalhadores gastam tudo o que ganham", com sua propensão a poupar igual a zero.

Por outro lado, iremos assumir que os capitalistas produtivos (ou seja, os proprietários das empresas não-financeiras da economia) têm uma propensão a poupar sobre o lucro líquido distribuido ${ }^{4}$ igual à $\mathrm{s}_{\mathrm{c}}$ e que os capitalistas produtivos possuem um estoque de títulos do governo herdado do período anterior igual a $\mathrm{B}_{\mathrm{c}}$. Sobre este estoque incide uma taxa de juros de longo-prazo (determinada pelo mercado) $i_{t-1}^{l p}$, de forma que os capitalistas produtivos obtém uma renda do governo igual $\left(i_{t-1}^{\text {lp }} B_{C}\right)$.

Por fim, iremos supor que os capitalistas financeiros (ou seja, os proprietários dos bancos) têm uma propensão a poupar sobre a receita liquida das operações de intermediação financeira igual $\mathrm{a} \mathrm{s}_{\mathrm{f}}$. As receitas líquidas de intermediação financeira incluem os juros recebidos pelos bancos

4 Iremos supor que o coeficiente de retenção de lucros é igual a $\vartheta$ 
do exterior em função do estoque de títulos estrangeiros que os mesmos mantêm em suas carteiras de ativos, $E B_{b}^{*}$. Os capitalistas financeiros também possuem títulos do governo na sua carteira de ativos num montante igual a $B_{f}$. A renda de juros obtida pelos capitalistas financeiros é igual a $\left(i_{t-1}^{l p} B_{f}\right)$. Deste modo, os gastos nominais de consumo no período $t$ são determinados pela seguinte expressão:

$P_{t} C_{t}=w_{t-1} N_{t-1}+\left(1-s_{c}\right)(1-\tau)\left\{(1-\vartheta) R_{1}+B_{C} i_{t-1}^{p}\right\}+\left(1-s_{f}\right)(1-\tau)\left(L_{t-1} i_{t-1}+i_{t-1}^{*} E B_{b}^{*}+i_{t-1}^{l p} B_{f}\right)$

Sendo $\quad R_{1} \equiv\left(P_{t-1} Y_{t-1}-w_{t-1} N_{t-1}-\left(i_{t-1}+\gamma\right) L_{t-1}\right)+i_{t-1}^{*} E B_{e}^{*}$.

\subsection{Alocação de Portfólio}

No início de cada período os agentes decidem a composição do seu portfólio para o período em consideração. A totalidade da riqueza financeira $\mathrm{V}$ deve ser alocada entre quatro ativos: moeda manual (H), moeda escritural (M), títulos públicos (B) e moeda estrangeira (E.R). Vamos considerar que o único parâmetro observado pelos agentes em sua decisão de portfólio é a rentabilidade relativa dos ativos, os quais são supostos substitutos imperfeitos entre si.

A decisão de alocação de portfólio será modelada por intermédio de uma função matemática que atenda aos seguintes requisitos:

(i) Seja função somente das remunerações dos ativos, e determine os percentuais de alocação da riqueza para cada um dos ativos;

(ii) Possa ser adaptada para cada um dos agentes, conforme a disponibilidade de ativos;

(iii) Seja facilmente inversível, uma vez que, ex ante, utilizaremos a mesma função para resolver o problema da remuneração dos ativos para o período seguinte;

(iv) Torne as decisões de alocação em um determinado ativo independentes das remunerações de outros, caso eles não participem da cesta de investimento de um determinado agente;

(v) Permita a calibração, uma vez que a utilização da mesma função para todos os ativos forçaria um alinhamento artificial de suas remunerações;

(vi) Utilize totalmente a disponibilidade orçamentária do agente.

$\mathrm{Na}$ revisão da literatura de modelos SFC não encontramos opções de funcionais que cumprissem os requisitos acima. Em alguns casos apenas um ativo financeiro está disponível, como no modelo de Dos Santos e Zezza (2007); em outros, todos os ativos estão disponíveis para os agentes, como em Godley e Lavoie (2007); ou ainda, as opções de alocação de portfólio não são livres, tendo equações comportamentais ad-hoc anexadas, de forma que sua determinação não se dá pelo mecanismo de livre mercado que utilizamos aqui. 
A opção encontrada foi então um funcional vetorial do espaço de remunerações para o espaço de alocações percentuais, $\wp: \Re^{4} \rightarrow \delta^{4}$, onde $\delta^{4}$ é o simplex unitário em $\Re^{4}$, ou seja:

$\delta^{4}=\left\{(x, y, z, w) \in \mathfrak{R}_{+}^{4} / x+y+z+w=1\right\}$

Selecionamos a função trigonométrica arco-tangente por ela apresentar as características consideradas necessárias, e ser de manipulação mais simples que sua contraparte exponencial (trigonométricas hiperbólicas). Ajustamos o domínio, para que exista a possibilidade de calibragem. Tomando-se $f$ como a proporção alocada em um determinado ativo, e $r$ como a remuneração daquele ativo, e $\delta$ como o fator para calibragem, a função básica é:

$f=\frac{1}{2 \pi}\{2 a \tan (\delta . r)+\pi\}$

Figura 1 - Função básica de alocação de portfólio, $\mathbf{f}$ percentual investido, $\delta$ parâmetro de calibragem, $\mathbf{r}$ remuneração.

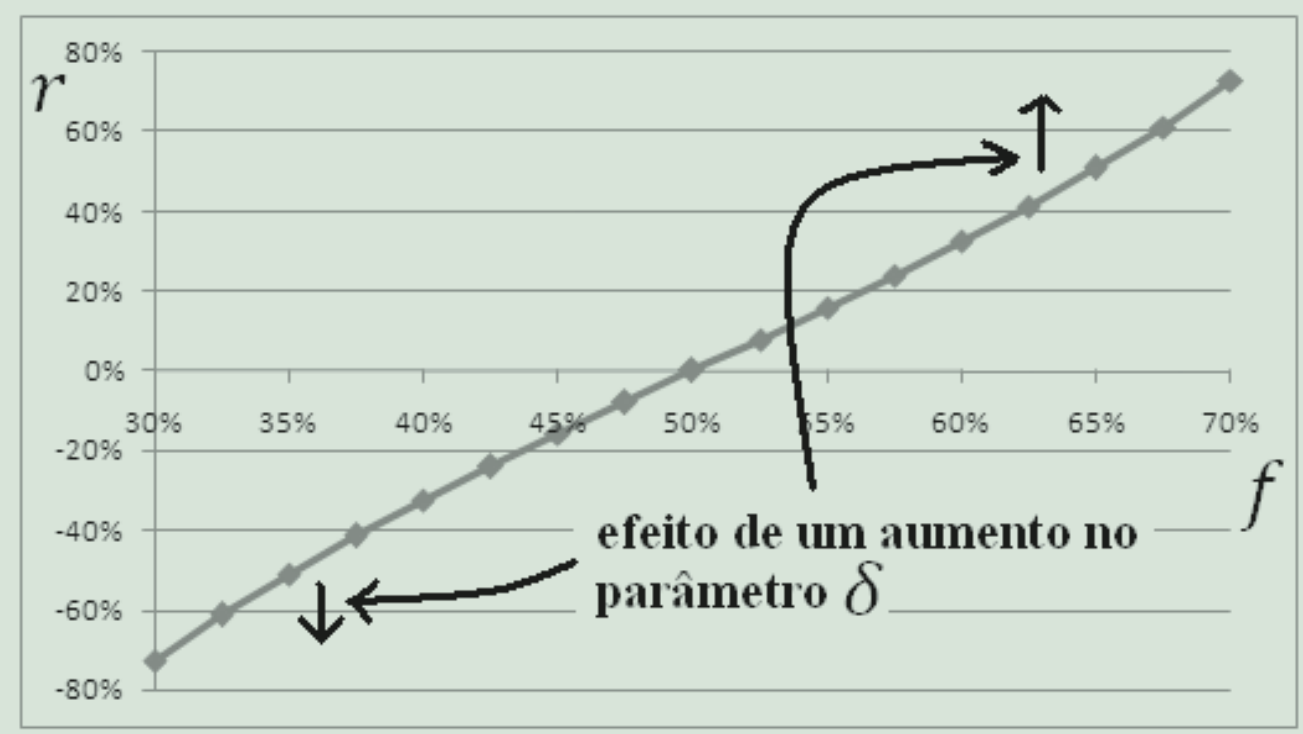

O parâmetro $f$ é, na realidade, um peso na alocação da riqueza de um agente naquele ativo. Por exemplo, se estão disponíveis dois ativos, ambos com peso $60 \%$ em nossa função de alocação, teremos uma distribuição igualitária da riqueza entre eles. A posição intermediária, $f=50 \%$, pode ser deslocada para cima alterando-se o cálculo da remuneração, tal como $r^{t}=r-\bar{r}$, onde r ré a nova posição neutra. Com uma função "peso" de alocação para cada ativo, $f \in(0,1)$, uma operação de média ponderada bastará para consumirmos totalmente a restrição orçamentária, $V$. Nesta média ponderada caberá a adaptação para cada agente: aos capitalistas produtivos, por exemplo, não é permitida a manutenção de saldos em moeda estrangeira, $E R$. Utilizamos no cálculo da média ponderada apenas os pesos da alocação dos títulos do governo, $f_{b}$, da moeda manual, $f_{b}$, e da moeda escritural, $f_{m}$. Como cada função básica tem apenas as remunerações dos seus ativos como entrada, a alteração da remuneração relativa da moeda estrangeira não influenciará na decisão dos capitalistas produtivos. 
A Tabela 2 apresenta a remuneração de cada um dos ativos da economia em consideração.

\section{Tabela 2 | Remunerações esperadas dos ativos.}

\begin{tabular}{|l|l|}
\hline Ativo & Remuneração \\
\hline Títulos do Governo, $B$ & $i_{g}^{e}-\pi^{e}$ \\
\hline Divisa Estrangeira, $E R$ & $\hat{E}^{e}+\pi^{e}-\pi^{* e}$ \\
\hline Moeda Manual, $H$ & $g_{y}^{e}$ \\
\hline Moeda Escritural, $M$ & $g_{y}^{e}+i_{b}^{e}$ \\
\hline
\end{tabular}

Fonte: Elaboração própria.

Onde os sobrescritos "e" significam esperado, uma vez que no início do período não há certeza sobre os valores que serão efetivamente pagos, muito embora a própria decisão dos agentes, junto com as ofertas de cada um dos ativos, mais ou menos elásticas de acordo com cada mercado, causarão a determinação das remunerações eficazes. Não poderíamos ficar com as oito incógnitas, pois haveria indeterminação. Os valores esperados são calculados em um esquema de expectativas adaptativas de um período, $\operatorname{com} \beta$ igual a 0,5. Desta forma, o funcional de

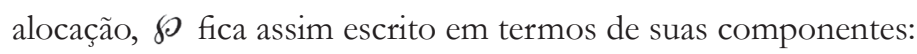

$f_{b}=\frac{2 a \tan \left(\delta_{b}\left(i_{g}-\pi^{e}\right)\right)+\pi}{2 \pi}$

$f_{e r}=\frac{2 a \tan \left(\delta_{e r}\left(\hat{E}+\pi^{e}-\pi^{* e}\right)\right)+\pi}{2 \pi}$

$f_{h}=\frac{2 a \tan \left(\delta_{h} g_{Y}^{e}\right)+\pi}{2 \pi}$

$f_{m}=\frac{2 a \tan \left(\delta_{m}\left(g_{Y}^{e}+i_{g}^{e}\right)\right)+\pi}{2 \pi}$

Para encontrarmos, por exemplo, a decisão dos capitalistas produtivos de investir em $B$, uma vez que possuem riqueza $V_{c}$ e que tem acesso à $B, H$ e $M$, fazemos:

$B_{c}=\left(\frac{f_{b}}{f_{b}+f_{h}+f_{m}}\right) Y_{c}$

Observe que nos mercados para $H$ e $M$ temos dois market makers, quais sejam o Banco Central e os Bancos Comerciais, os quais fixam os valores da taxa de juros de curto-prazo e da taxa de juros dos empréstimos bancários, respectivamente. Desta forma a decisão de portfólio dos agentes é o que determina os estoques desses ativos. Já nos mercados de ER e $B$, temos um encontro de vontades em mercados competitivos, o primeiro do excedente ou de ausência de divisas, que podem vir a ser adquiridas, ou fornecidas por agentes privados, e o segundo com 
base nas necessidades de financiamento do governo. Nestes dois mercados competitivos apenas um preço de equilíbrio causará a liquidação. Utilizamos as inversões das funções "peso" $f_{b}$ e $f_{e r}$ (uma vez que conhecemos o percentual da riqueza dos agentes que necessitará ser alocado em cada um dos ativos para a liquidação dos mercados), e calculamos a remuneração dos títulos do governo (a taxa de juros de longo-prazo), $i_{g}$, e a taxa de depreciação do câmbio nominal, $\hat{E}$.

$i_{g}=\pi^{e}+\frac{1}{\delta_{b}} \tan \left(\frac{2 \pi f_{b}-\pi}{2}\right)$

$\hat{E}=\pi^{* e}-\pi^{e}+\frac{1}{\delta_{e r}} \tan \left(\frac{2 \pi f_{e r}-\pi}{2}\right)$

\subsection{Setor Externo}

A taxa de inflação internacional é dada por $\pi^{*}$, uma variável aleatória que flutua em torno de uma média constante $\bar{\pi}^{*}$ :

$\pi_{t}^{*}=\pi^{*}+\epsilon(t)$

$P_{t}^{*}=\left(1+\pi_{t}^{*}\right) P_{t-1}^{*}$

O crescimento econômico do resto do mundo também é considerado uma variável aleatória de média $g^{*}$ :

$g_{t}^{*}=g^{*}+\in(t)$

$Y_{t}^{*}=\left(1+g_{t}^{*}\right) Y_{t-1}^{*}$

O quantum importado é dado pela função abaixo que apresenta elasticidade-câmbio real constante e igual a $-\chi$ e elasticidade-renda nacional constante e igual a $\in$ :

$M_{t}=j\left(\frac{P_{t-1}}{E_{t-1} P_{t-1}^{*}}\right)^{-\chi} Y_{t-1}^{\epsilon}$

De maneira simétrica o quantum exportado é dado por uma função de elasticidade-câmbio real constante e igual a $\Omega$ e elasticidade-renda do resto do mundo constante e igual a $v$ :

$X_{t}=x\left(\frac{E_{t-1} P_{t-1}^{*}}{P_{t-1}}\right)^{\Omega}\left(Y_{t-1}^{*}\right)^{v}$

E assim temos todos os elementos para a função demanda efetiva:

$Z(t)=C^{w}(t)+C^{P}(t)+C^{f}(t)+I^{e}(t)+C^{g}(t)+I^{g}(t)+X(t)-e(t) M(t)$ 


\section{SIMULAC̣ÃO COMPUTACIONAL DO MODELO TEÓRICO.}

\subsection{Calibragem}

Calibramos nosso modelo para que ele se comporte da maneira mais similar possível aos seus precedentes diretos na literatura, ou seja, Oreiro e Passos (2008) e Sarquis e Oreiro (2009), usando parâmetros idênticos, quando possível. Há, entretanto, uma dinâmica própria, de forma que calibragens mais cuidadosas podem ter afastado os parâmetros utilizados aqui daqueles encontrados nas referências. Optamos por abandonar a característica estocástica daqueles modelos de forma a facilitar a análise por resposta à função degrau apresentada abaixo.

Quadro 1 | Parâmetros do Modelo

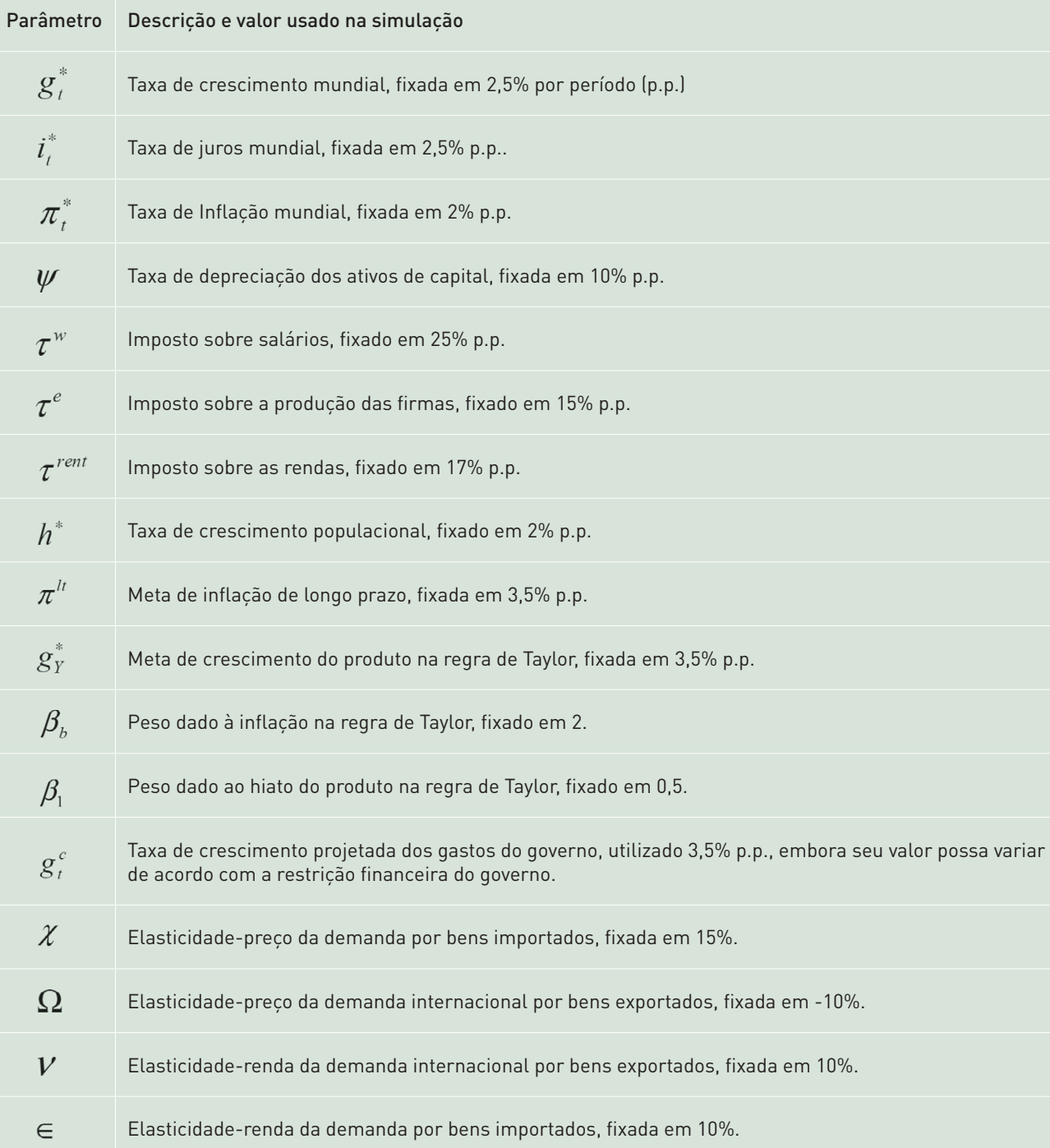

Fonte: Elaboração própria. 


\subsection{Comportamento da Simulação Padrão}

A simulação padrão contou com a interação do modelo por 80 períodos ${ }^{5}$. Algumas características marcantes da mesma foram, conforme figura 2 abaixo, o crescimento não-explosivo, porem irregular, do produto, o que é um dos fatos estilizados da dinâmica das economias capitalistas (Blanchard e Fisher, 1989). Percebe-se também a raridade de grandes quedas do nível de produto (uma depressão), o que é outro fato estilizado da dinâmica das economias capitalistas (Leijonhfvud 1996).

\section{Figura 2 | Taxa de Crescimento do Produto Real, por período de simulação, a partir do décimo.}

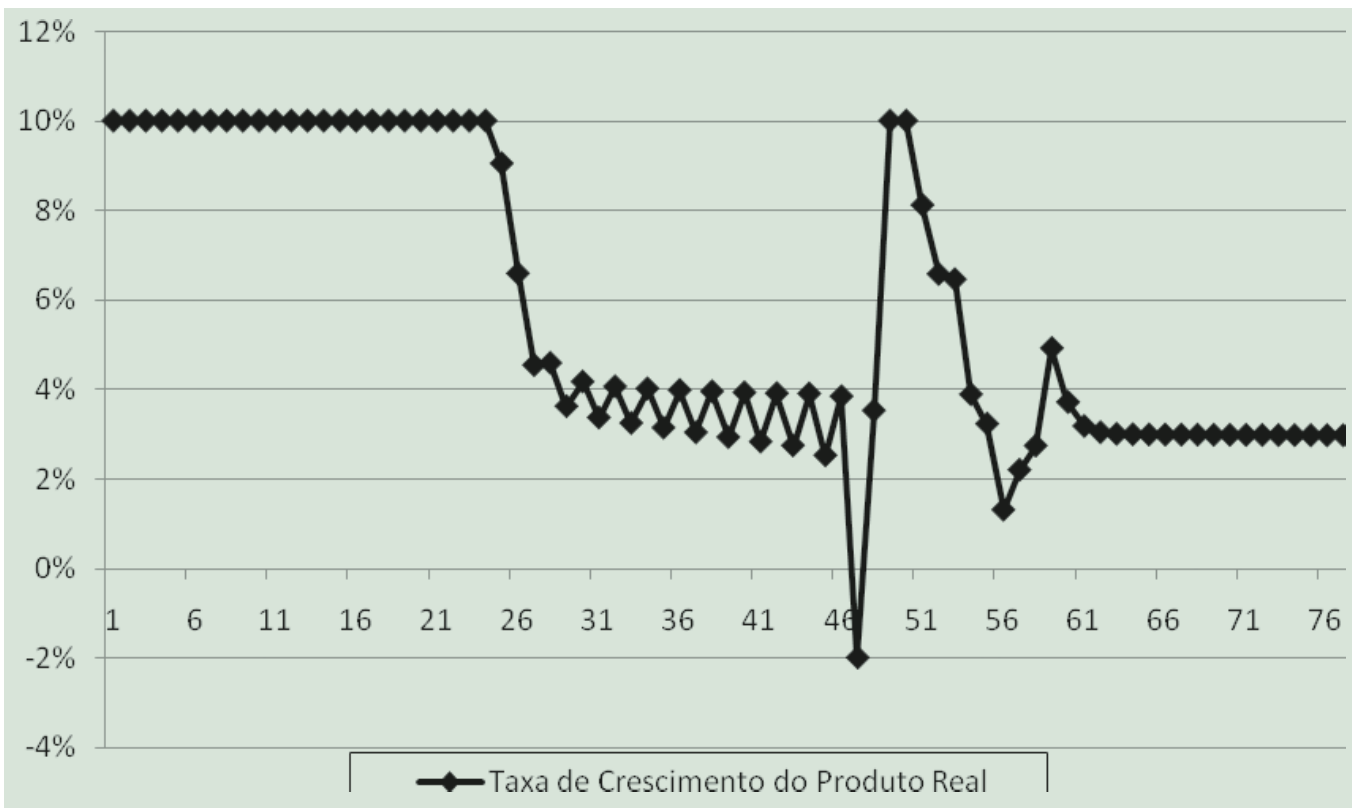

$\mathrm{Na}$ figura 3 observa-se que a economia em consideração tende a operar com sub-utilização persistente de capacidade produtiva. Com efeito, o grau de utilização da capacidade só foi igual ao máximo entre os períodos 26 e 46. Nos demais períodos, o grau de utilização da capacidade foi menor do que o máximo.

5 Os primeiros 10 períodos de simulação são tomados por forte flutuação. Esses períodos foram excluídos dos gráficos abaixo, pois representam mais uma acomodação das variáveis aos seus valores mais apropriados do que dinâmica intrinsecamente modelada. 
Figura 3 | Utilização da Capacidade Instalada no Período, a partir do décimo

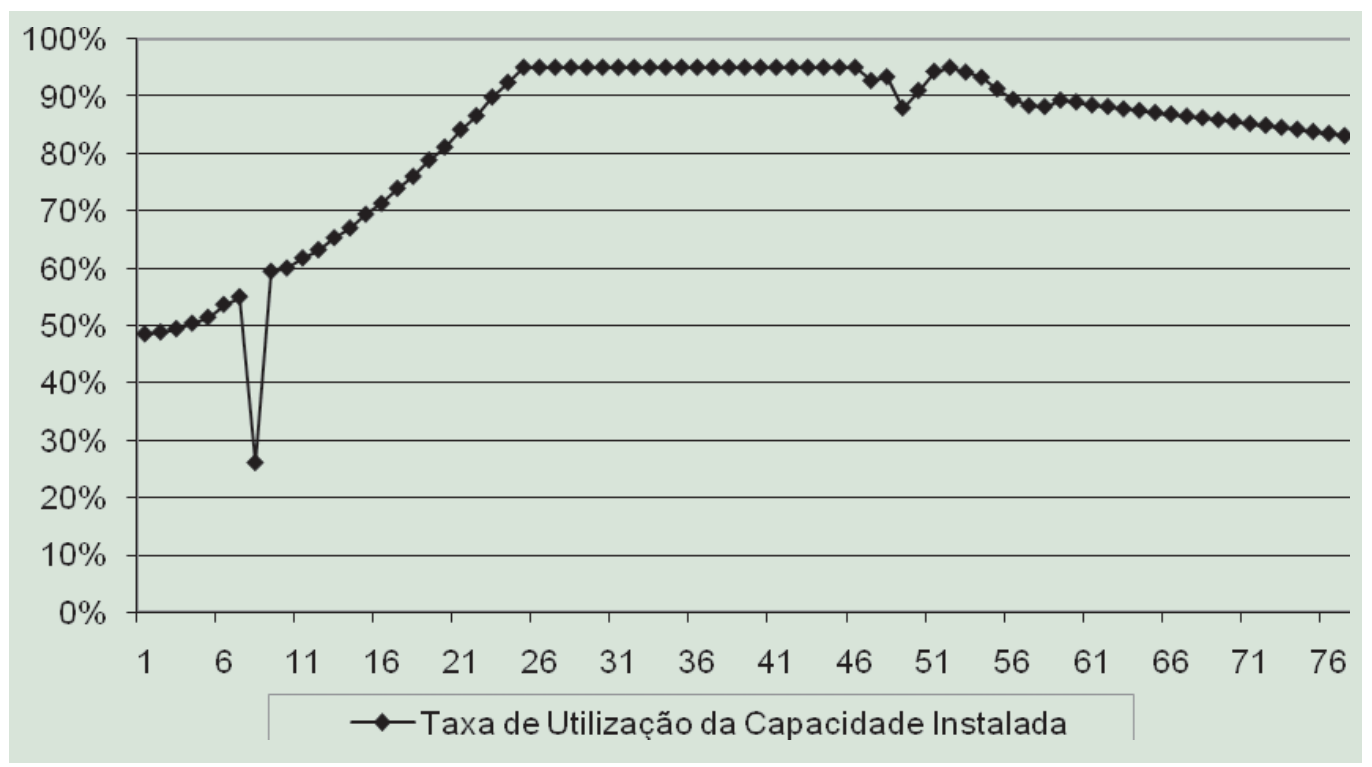

$\mathrm{Na}$ figura 4 observamos uma característica importante da dinâmica das economias capitalistas, ao menos naquilo que Kaldor (1957b) denominou de fase II do capitalismo, a saber: o crescimento dos salários reais num ritmo aproximadamente igual a taxa de expansão da produtividade do trabalho.

Figura 4 | Salário Real e Produtividade dos Trabalhadores, no período, a partir do décimo

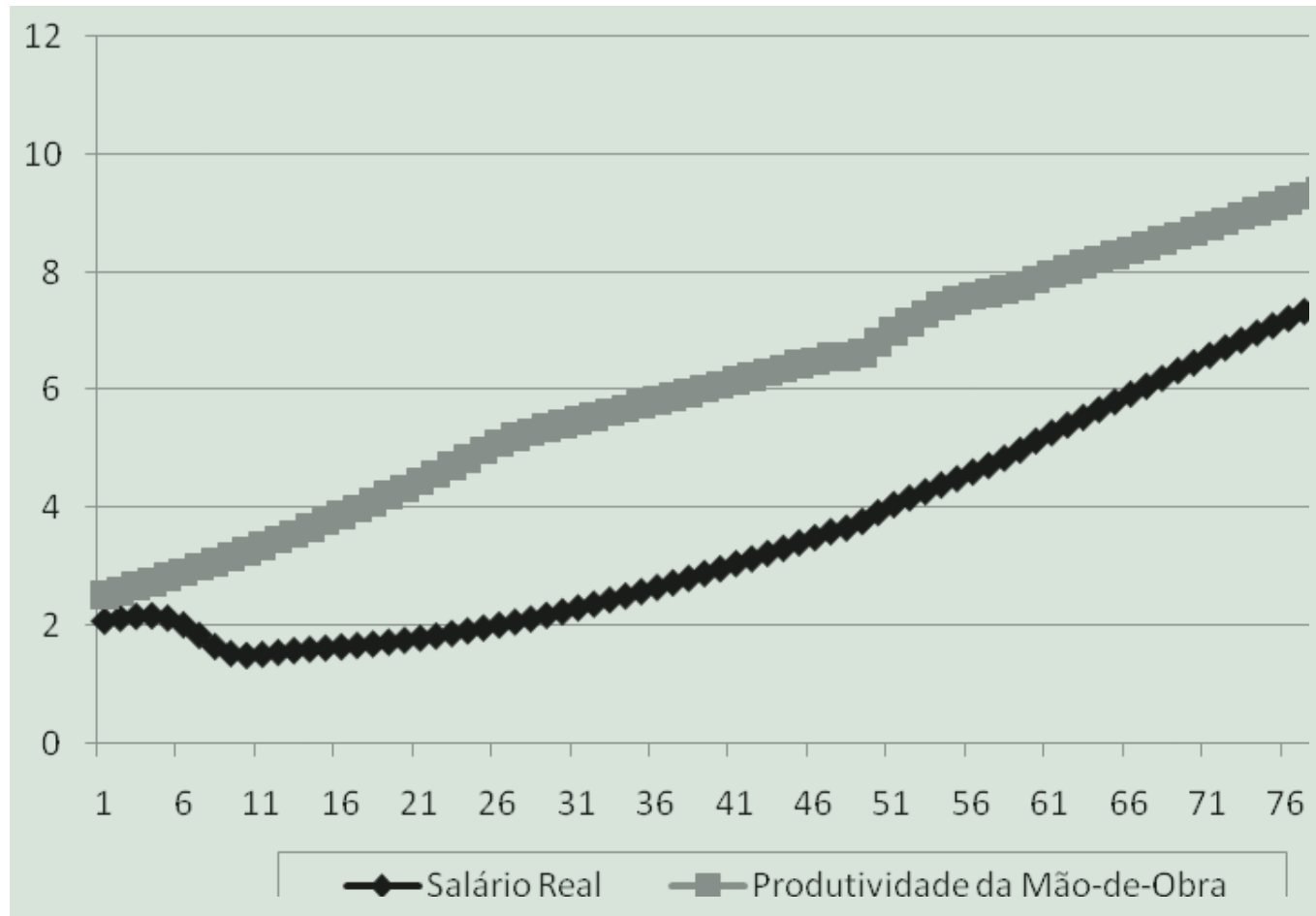


Na figura 5, observamos outro dos fatos estilizados de Kaldor (1957a), qual seja, a estabilidade da taxa de lucro no longo-prazo, de tal forma que as economias capitalistas não apresentam uma tendência a queda da taxa de lucro no longo-prazo.

Figura 5 | Taxa de lucro e Participação dos lucros na renda

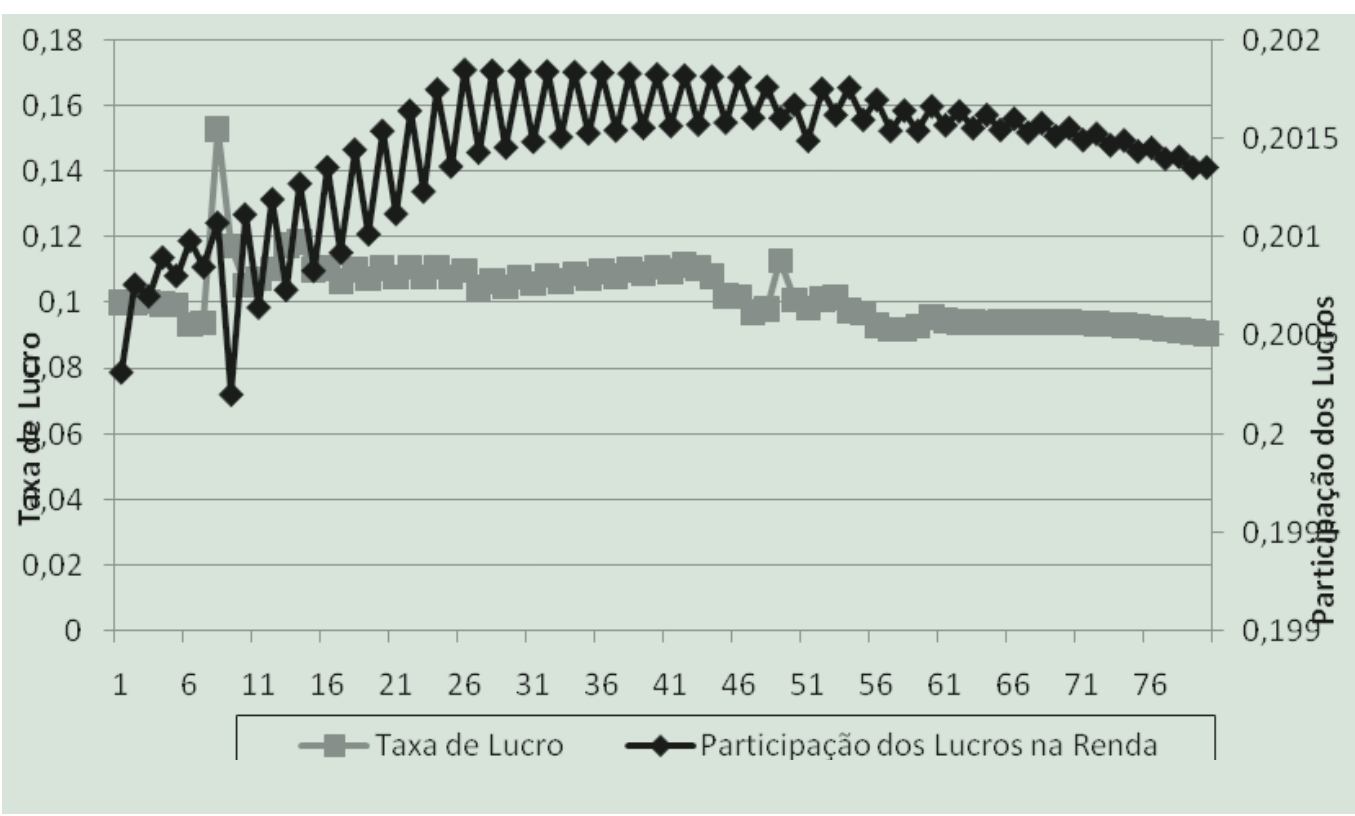

$\mathrm{Na}$ figura 6 observamos a dinâmica da taxa de juros de curto-prazo, do spread bancário e da taxa de inflação. Uma constatação importante a ser feita a partir da análise dessa figura é que a taxa de inflação parece ser relativamente pouco sensível às variações da taxa básica de juros. A explicação para isso se dá com base na constatação de que na economia em consideração a natureza do processo inflacionário é distinta daquela suposta nos manuais convencionais de macroeconomia. Com efeito, a inflação na economia em consideração resulta do conflito distributivo entre capitalistas e trabalhadores pela renda nacional. A taxa de juros pode forçar os trabalhadores a aceitar moderar as suas demandas salariais, mas apenas após um período relativamente longo de crescimento da taxa de desemprego. 
Figura 6 | Dinâmica da Taxa de Inflação, Taxa de Juros Básica e Spread Bancário, a partir do vigésimo período (em log)

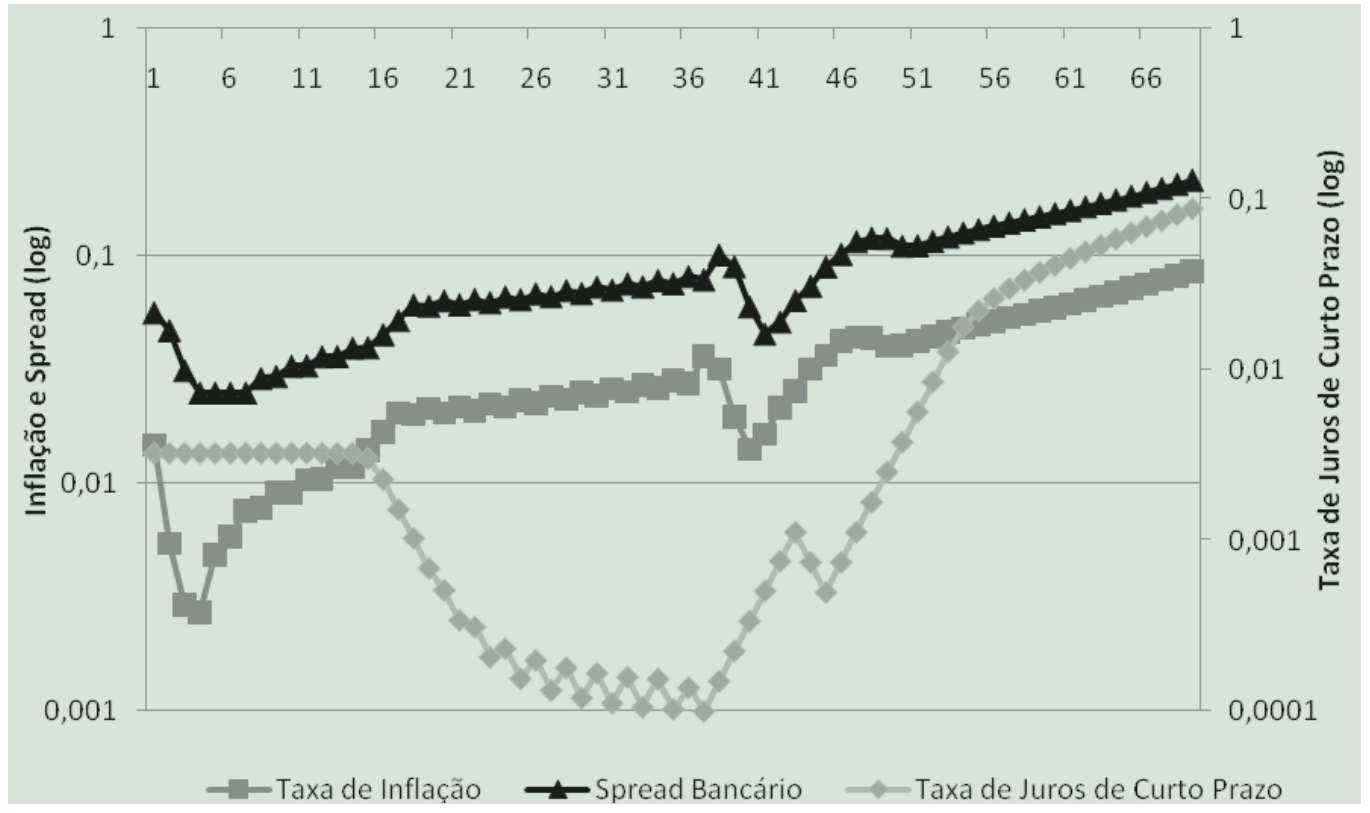

\section{CONCLUSÃO}

O objetivo fundamental deste artigo era construir um modelo macrodinâmico pós-keynesiano de simulação com consistência de estoque e fluxos para uma economia aberta com atividades governamentais, um regime de câmbio flutuante puro, metas de inflação, progresso técnico endógeno e mobilidade imperfeita de capitais. Esse modelo é pensado para ser um arcabouço teórico capaz de integrar os aspectos real e financeiro da economia pós-keynesiana, fazendo assim algum progresso no sentido de responder a crítica de Solow (1979) segundo a qual a economia póskeynesiana seria apenas um "estado de espírito", ao invés de um desafio coerente ao mainstream.

As trajetórias simuladas refletem algumas propriedades gerais da dinâmica capitalista, especialmente a existência de flutuações irregulares, mas não explosivas, da taxa de crescimento do produto real. Observou-se também a possibilidade de ocorrência de uma queda abrupta do nível de produção (uma depressão) a partir da dinâmica endógena do modelo. Outros resultados importantes foram: a tendência a sub-utilização da capacidade produtiva ao longo do tempo, a tendência dos salários reais crescerem ao mesmo ritmo da produtividade do trabalho, a estabilidade da taxa de lucro no longo-prazo e a pouca eficácia da taxa básica de juros como instrumento de controle inflacionário numa economia onde a inflação decorre fundamentalmente do conflito distributivo entre capitalistas e trabalhadores.

O modelo apresentado neste artigo pode ser usado para avaliar os efeitos de mudanças de política econômica - por exemplo, um aumento da taxa de crescimento dos gastos de consumo 
corrente do governo ou um aumento da meta inflacionária - sobre a dinâmica das variáveis endógenas. Esse exercício, contudo, por falta de espaço, não poderá ser realizado neste artigo.

\section{Apêndice A. Demonstrativo de Resultados da Economia}

\begin{tabular}{|c|c|c|c|c|c|c|c|c|c|c|}
\hline \multirow{2}{*}{ Fluxos } & \multirow{2}{*}{ Trab. } & \multirow{2}{*}{$\begin{array}{c}\text { Cap. } \\
\text { Produtivos }\end{array}$} & \multirow{2}{*}{$\begin{array}{c}\text { Cap. } \\
\text { Financeiros }\end{array}$} & \multicolumn{2}{|c|}{ Firmas } & \multirow{2}{*}{ Bancos } & \multirow{2}{*}{$\begin{array}{l}\text { Banco } \\
\text { Central }\end{array}$} & \multirow[b]{2}{*}{ Governo } & \multirow{2}{*}{$\begin{array}{l}\text { Setor } \\
\text { Externo }\end{array}$} & \multirow{2}{*}{ Total } \\
\hline & & & & Corrente & Capital & & & & & \\
\hline Cons. & $\begin{array}{c}(-) \\
\text { p.Cw }\end{array}$ & $(-) p . C c$ & (-)p.Cf & $\begin{array}{l}\text { p.C+(E.X- } \\
\text { E.p*.M) }\end{array}$ & 0 & 0 & 0 & (-)p.Cg & E.p.M - E.X & 0 \\
\hline Invest. & 0 & 0 & 0 & p.le+p.lg & (-) p.le & 0 & 0 & (-)p.lg & 0 & 0 \\
\hline Salários & W & 0 & 0 & $(-) W$ & 0 & 0 & 0 & 0 & 0 & 0 \\
\hline Impostos & $(-) T w$ & (-)TC & (-)Tf & (-)Te & 0 & $(-) \mathrm{Tb}$ & 0 & T & 0 & 0 \\
\hline $\begin{array}{l}\text { Insumos } \\
\text { Importados }\end{array}$ & 0 & 0 & 0 & (-JRm.E.p* & 0 & 0 & 0 & 0 & Rm.E.p* & 0 \\
\hline $\begin{array}{l}\text { Juros s/ } \\
\text { Emprest. }\end{array}$ & 0 & 0 & 0 & $(-)$ ib.L(-1) & 0 & $\begin{array}{l}\text { ib.L(-1) - } \\
\text { ibc.A(-1) }\end{array}$ & ibc.A(-1) & 0 & 0 & 0 \\
\hline $\begin{array}{l}\text { Juros s/ } \\
\text { Títulos }\end{array}$ & 0 & ig.Bc(-1) & ig.Bf(-1) & 0 & 0 & ig.Bb(-1) & ig.Bbc(-1) & $\underset{(-1)}{(- \text { lig.B }}$ & 0 & 0 \\
\hline $\begin{array}{l}\text { Juros s/t } \\
\text { Tit. Ext. }\end{array}$ & 0 & 0 & 0 & $\begin{array}{c}(-) \\
i^{*} \cdot E \cdot B^{*} e(-1)\end{array}$ & 0 & $\begin{array}{c}(-) \\
i^{*} \cdot E \cdot B^{*} b(-1)\end{array}$ & 0 & 0 & $i^{*} \cdot E \cdot B^{*}(-1)$ & 0 \\
\hline Dividendos & 0 & $\mathrm{Fe}$ & $\mathrm{Fb}$ & (-) Fe & 0 & $(-) F b$ & $(-) F b c$ & $\mathrm{Fbc}$ & 0 & 0 \\
\hline$\Delta \mathrm{E}-$ var camb. & 0 & 0 & 0 & 0 & $\Delta \mathrm{E} \cdot \mathrm{B}^{*} \mathrm{e}(-1)$ & $(-) \Delta \mathrm{E} \cdot \mathrm{Rb}(-1)$ & $\begin{array}{c}(-) \\
\Delta \mathrm{E} \cdot \mathrm{Rbcl}-1)\end{array}$ & 0 & $\begin{array}{c}\Delta \mathrm{E} \cdot(\mathrm{R}(- \\
\left.1)-\mathrm{B}^{*}(-1)\right)\end{array}$ & 0 \\
\hline $\begin{array}{l}\Delta p \text { - correção } \\
\text { monetária }\end{array}$ & 0 & 0 & 0 & 0 & п.р(-1).K(-1) & 0 & 0 & 0 & 0 & $\begin{array}{c}\text { ח.p } \\
(-1) \cdot K(-1)\end{array}$ \\
\hline$\Psi$ - depreciação & 0 & 0 & 0 & 0 & $(-) \psi \cdot K(-1)$ & 0 & 0 & 0 & 0 & $(-) \psi \cdot K(-1)$ \\
\hline $\begin{array}{l}\text { Savings - } \\
\text { poupança corrente }\end{array}$ & 0 & Sc & Sf & Se & 0 & 0 & 0 & $\mathrm{Sg}$ & $\mathrm{S}^{*}$ & S \\
\hline
\end{tabular}

Obs.: O sinal (-) representa um desembolso. 


\section{REFERÊNCIAS BIBLIOGRÁFICAS}

BLANCHARD, O;. FISHER, S. (1989). "Lectures on Macroeconomics". MIT Press: Cambridge.

CARVALHO, F.C. (1992). Mr Keynes and the Post Keynesians: principles of macroeconomics for a monetary production economy. Edward Elgar: Aldershot

DAVIDSON, P. (1968). "Money, Portfolio Balance, Capital Accumulation, and Economic Growth". Econometrica, 367, abril, p. 291-321.

DAVIDSON, P. (1972). "Money and the Real World". Armonk, NY: M.E. Sharpe.

(2002). Financial Markets, Money and the Real World. Edward Elgar: Alderhot.

DOS SANTOS, C. H. (2005). "A stock-flow consisten general framework for formal Minskyan analyses of closed economies", Journal of Post-Keynesian Economics, 27(4): 11-35.

DOS SANTOS, C.H. (2006). "Keynesian Theorizing during hard times: stock-flow consistent models as an 'unexplored frontier' of Keynesian macroeconomics". Cambridge Journal of Economics, Vol. 30, N.4.

DOS SANTOS, C. H.; ZEZZA, G. (2008). "A Simplified "Benchmark" Stock-flow Consistent (SFC) Post-Keynesian Growth Model". Metroeconomica, 59: 441-478.

DOS SANTOS, C.H; MACEDO SILVA, A.C. (2009). "Revisiting (and connecting) Marglin-Bhaduri and Minsky: a SFC look at financialization and profit-led growth". Anai. do II Encontro Internacional da Associação Keynesiana Brasileira, Porto Alegre.

DOS SANTOS, C. H; MACEDO SILVA, A. C. M. (forthcoming). "Revisiting (and connecting) Marglin-Bhaduri and Minsky: a SFC look at financialization and profit-led growth".

GODLEY, W; LAVOIE, M. (2007). Monetary Economics: an integrated approach to credit, money, income, production and wealth. Palgrave Macmillan: Londres

GOODWIN, R. (1967). "A Growth Cycle" In: Essays in Economic Dynamics. MacMillan: London.

HARCOURT, G. (2006). The Structure of Post Keynesian Thought. Cambridge University Press: Cambridge

KALDOR, N. (1956). "Alternative Theories of Distribution”. Review of Economic Studies, v. 23, p.83-100, 1956

Economic Journal, vol. 67, n. 268, p591-624.

(1957b) "Capitalist Evolution in the Light of Keynesian Economics”. Sankbyã, Maio.

KALECKI, M. (1954). "Theory of Economic Dynamics an essay on cyclical and long run changes in capitalist economy". London: Allen \& Unwin.

LEIJONHFVUD, A. (1996) Towards a Not Too Rationa Macroeconomics. In: COLLANDER, D. (ed.) Beyond Microfundations: post walrasian macroeconomics. Cambridge: Cambridge University Press.

MINSKY, H. P. (1975). “John Maynard Keynes”, New York, Columbia University Press.

OREIRO, J.L; ONO, F.H. (2007). "Um Modelo Macrodinâmico Pós-Keynesiano de Simulação”. Revista de Economia Politica, Vol. 27, N.1.
OREIRO, J. L. C. ; PASSOS, M. O. (2008) “Um modelo macrodinâmico estocástico de simulação para uma economi aberta”. Econômica (Niterói), v. 10, p. 79-122.

OREIRO, J.L; LEMOS, B.P. (2009). "Crescimento e Flutuacões num modelo pós-keynesiano de simulacão com progresso técnico endógeno e endividamento público". Análise

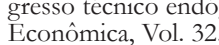

PASINETTI, L. (1962). "Rate of Profit and Income Distribution in Relation to the Rate of Economic Growth". Review of Economic Studies, 29, p. 267-79, 1962.

(1997). "The Principle of Effective Demand" In: HARCOURT, G.; RIACH, P.A. A Second Edition of The General Theory. Routledge: London.

POSSAS, M. (1993). "Racionalidade e Regularidades: Rumo à Integração Micro-Macrodinâmica" Economia e Sociedade, 2, p. $59-80$.

SAMUELSON, P. (1939). "Interactions between the Multiplier and the Principle of Acceleration". Review of Economic Studies, 21.

SETTERFIELD, M. (2006). "Is Inflation Targeting Compatible with Post Keynesian Economics?". Journal of Post Keynesian Economics, 28

SIMON, H. (1980). “A Racionalidade do Processo Decisório em Empresas”. Edições Multiplic, vol.1, $\mathrm{n}^{\circ} 1$.

SOLOW, R. (1979). "Alternative Approaches to Macroeconomic Theory: a partial view". Canadian Journal of Economics, 12 , pp.339-354.

TAYLOR, J. (1993)."Discretion versus Policy Rules in Practice". Carnegie-Rochester Conference Series on Public Policy, 39, 195-214.

TOBIN, J. (1982). "Money and Finance in the Macroeconomic process". Journal of Money, Credit and Banking, Vol. 1, N.1.

ZEZZA, G; DOS SANTOS, C.H. (2004). "The role of monetary policy in post-keynesian stock-flow consistent macroeconomic models" In LAVOIE, M; SECCARECCIA, M (orgs.). Central Banking in the Modern World: alternative perspectives. Edward Elgar: Aldershot.

CROTTY, J. R. E GOLDSTEIN, J. P. (1992). The Investment Decision of the Post-Keynesian Firm: A Suggested Microfoundation for Minsky's Investment Instability Thesis. Levy Economics Institute Working Paper No. 79. Disponível em SSRN: http:// ssrn.com/abstract=160351 or do1:10.2139/ssrn.16035 
